\title{
Review of Parotid Biopsy Techniques
}

Shah, $\mathrm{R}^{1}$., Zhang, $\mathrm{T}^{2}{ }^{2}$, Kirkland, $\mathrm{P}^{3}$. and Howlett, $\mathrm{D}^{4}$.

1.East Sussex Healthcare NHS Trust, Core Surgical Trainee

2. East Sussex Healthcare NHS Trust, Radiology Registrar

3.East Sussex Healthcare NHS Trust, Consultant ENT Surgeon

4. East Sussex Healthcare NHS Trust, Consultant Radiologist

\section{Introduction and Background}

A lump in the head and neck region is one of the most common presentations

- $80 \%$ of salivary neoplasms arise in the parotid

- Ultrasound in the investigation of choice for parotid glands

- Fine Needle Aspiration Cytology (FNAC) gained popularity in the 1980s to diagnose parotid lesions.

- Surgical exploration carried the risk of infection, tumour seeding, facial nerve injury and fistula formation

- Ultrasound (US) is currently the investigation of choice when dealing with the parotid glad.

- Ultrasound Guided Core Needle Biopsy (USGCNB) has gained popularity in recent years. It is routinely used in liver and breast biopsies.

\section{Objective}

- Review different techniques of parotid biopsy

- To evaluate the efficacy of FNAC versus Ultrasound Guided Core Needle Biopsy (USGCNB)
Advantages of USGCNB over FNAC

\section{$\underline{\text { Results and Analysis }}$}

Larger sample sizes - lower sample inadequacy allowing immunohistochemical analysis

- Higher sensitivity, specificity and accuracy (up to $98 \%$, $100 \%$ and $96 \%$ respectively)

FNAC has a higher rate of variability leading to inaccuracy of diagnosis

- Better in routine diagnosis (pleomorphic adenoma, Warthin's tumours and lymphoma)

Lower rate of sample inadequacy

USGCNB is better at diagnosing malignancy compared to FNAC

\section{Advantages of FNAC over USGCNB}

$>$ FNAC reported as less painful by patients

$>$ Potential seeding risk associated with USGCNB

$>$ Lidocaine (or local anaesthetic) is used in USGCNB and this has a theoretical risk of increased morbidity

\section{Discussion}

- FNAC has difficulty diagnosing pleomorphic adenoma, basal cell adenoma and squamous cell carcinoma

- Injury to facial nerve can be avoided under ultrasound guidance

- Authors analysed data from key studies and established recommendations.

- Studies involved in the analysis were obtained from a literature search using pubmed, medline and embase.

- Key words used were 'parotid gland', 'biopsy', 'technique'.

- Authors supplemented search by input from experts in the field

- Exclusion criteria was determined.

12 studies were analysed

\section{Conclusion}

- We recommend USGCNB as a diagnostic tool

- Access to USGCNB and FNAC should determine the use, especially in smaller departments.

References 1. GUDMUNDSSONJK, AJAN A, ABTAHI J. The accuracy of fine-needie aspiration cytology for diagnosis of
http $/$ www.scielo.br/scielo.php?script=sci_arttext\&pid=S1678-77572016000600561\&lng=en\&tlng=en 2. Kesse KW, Manjaly G, Violaris N, Howlett DC. Ultrasound-guided biopsy in the evaluation of focal lesions and diffuse swelling of the parotid gland. Br J Oral Maxillofac Surg. 2002;40(5):384-8. 2. Kesse KW, Manjaly G, Violaris N, Howlett DC. Ultrasound-guided biopsy in the evaluation of focal lesions and diffuse swelling of the parotid gland. Br J Oral Maxillofac Surg. 2002;40
3. Douville N, Bradford C. Comparison of ultrasound-guided core biopsy versus fine-needle aspiration biopsy in the evaluation of salivary gland lesions. Head Neck. 2015;1657-61.

4. Burke C, Thomas R, Inglis C, Baldwin A, Ramesar K, Grace R, et al. Ultrasound-guided core biopsy in the diagnosis of lymphoma of the head and neck. A 9 year experience. Br J Radiol. 2011;84(1004):727-32.

5. Huang YC, Wu C Te, Lin G, Chuang WY, Yeow KM, Wan YL. Comparison of ultrasonographically guided fine-needle aspiration and core needle biopsy in the diagnosis of parotid masses. J Clin Ultrasound. 2012;40(4):189-94. 6. Pfeiffer J, Ridder GJ. Diagnostic value of ultrasound-guided core needle biopsy in patients with salivary gland masses. Int J Oral Maxillofac Surg. 2012;41(4):437-43.

7. Schmidt RL, Hall BJ, Wilson AR, Layfield L. A systematic review and meta-analysis of the diagnostic accuracy of fine-needle aspiration cytology for parotid gland lesions. Am J Clin Pathol. 2011;136(1):45-59.

8. Haldar S, Mandalia U, Skelton E, Chow V, Turner SS, Ramesar K, et al. Diagnostic investigation of parotid neoplasms: A 16-year experience of freehand fine needle aspiration cytology and ultrasound-guided core needle biopsy. Int J Oral Maxillofac Surg [Internet]. 2015;44(2):151-7. Versus Fine Needle Aspiration Cytology for Diagnosing Salivary Gland Tumors. J Pathol Transl Med [Internet]. 2015;49(2):136-43. Available from: 